\title{
Maternal and child's vitamin D supplement use and vitamin $D$ level in relation to childhood lung function: the KOALA Birth Cohort Study
}

\author{
Elleke Cremers, ${ }^{1}$ Carel Thijs, ${ }^{1}$ John Penders, ${ }^{1,2}$ Eugene Jansen, ${ }^{3}$ Monique Mommers ${ }^{1}$
}

'Department of Epidemiology, Maastricht University, CAPHRI School for Public Health and Primary Care, Maastricht, The Netherlands

${ }^{2}$ Department of Medical Microbiology, Maastricht University, NUTRIM School for Nutrition, Toxicology and Metabolism, Maastricht, The Netherlands

${ }^{3}$ National Institute for Public Health and the Environment, Laboratory of Health Protection Research, Bilthoven, The Netherlands

\section{Correspondence to}

Monique Mommers,

Department of Epidemiology

Maastricht University, PO Box 616, 6200 MD Maastricht, The Netherlands;

monique.mommers@

maastrichtuniversity.nl

Received 24 September 2010 Accepted 3 February 2011 Published Online First 21 March 2011

\section{ABSTRACT}

Background Vitamin D is associated with lung function in adults, but its relation with childhood lung function is still unclear.

Objective To investigate whether prenatal and postnatal vitamin $\mathrm{D}$ supplementation and plasma level is associated with childhood lung function.

Methods In the KOALA Birth Cohort Study, children's lung function $(n=436)$ was measured at age $6-7$ years by means of spirometry and presented as forced expiratory volume in $1 \mathrm{~s}\left(\mathrm{FEV}_{1}\right) \mathrm{z}$ scores and forced vital capacity z scores. The mother and child's 25-hydroxyvitamin D plasma level was determined around 36 weeks of pregnancy and at age 2 years. Vitamin D supplement intake during pregnancy was defined based on the amount of vitamin $D$ in supplements, and trimester and duration of use. Data on child's vitamin $\mathrm{D}$ supplement use were collected through questionnaires at ages 1, 2 and $6-7$ years.

Results 25-Hydroxyvitamin D level and vitamin D supplement use in childhood were not associated with lung function. Maternal use of vitamin $D$ at $<10 \mu \mathrm{g} /$ day (adjusted beta (AdjB $-0.37 ; 95 \% \mathrm{Cl}-0.69$ to -0.05 )), vitamin $\mathrm{D}$ containing multivitamin use in the second and/ or third trimester (AdjB $-0.26 ; 95 \% \mathrm{Cl}-0.49$ to -0.03 ), and use for two trimesters (AdjB $-0.25 ; 95 \% \mathrm{Cl}-0.49$ to -0.02 ) were associated with a significantly lower $\mathrm{FEV}_{1}$ z score compared with no supplements. Maternal use of vitamin $D$ at $\geq 10 \mu \mathrm{g} /$ day and use in the first or all trimesters was not associated with significantly lower lung function levels.

Conclusion The authors found no association between 25-hydroxyvitamin D levels, vitamin D supplementation in childhood or recommended vitamin $D$ dosage of $\geq 10 \mu \mathrm{g} /$ day during pregnancy and lung function in children aged $6-7$ years.

\section{INTRODUCTION}

Determinants of pulmonary function in children are age, height and gender and it has become increasingly clear that antenatal and early life exposures are important influencing factors as well. Exposure to tobacco smoke, both prenatally and postnatally, ${ }^{12}$ and lower level of physical activity ${ }^{3}$ are well documented to reduce children's lung function. There is also evidence that a healthy maternal diet and high vitamin E levels during pregnancy, ${ }^{4} 5$ and a childhood diet consisting of a high intake of antioxidant vitamins, fruit and vegetables are associated with higher lung function levels. ${ }^{6}$

Lately the role of vitamin D in lung development and lung function is receiving increasing attention. ${ }^{7}$

\section{Key messages}

\section{What is the key question?}

Is there an association between vitamin $D$ supplement use and 25-hydroxyvitamin D level, during pregnancy and in childhood, and lung function level at school age?

\section{What is the bottom line?}

Vitamin D supplement use and 25-hydroxyvitamin D level during pregnancy and in childhood are not associated with lung function in school-aged children.

\section{Why read on?}

Although vitamin $D$ has been positively associated with lung function in adults, its relation with childhood lung function is still unclear.

Lung development begins in the uterus and continues through the first years of life. Postnatally, type II alveolar cells are responsible for proliferation of alveolar epithelium to maintain the integrity of the lung during growth, development, and in reaction to lung damage. ${ }^{8}$ Studies in fetal rat lung have identified alveolar type II cells as a target for vitamin $\mathrm{D}$ and have shown that vitamin $\mathrm{D}$ is important in surfactant production and lung maturation. $^{9-11}$ There is evidence that low maternal vitamin $\mathrm{D}$ status during pregnancy is associated with disturbances in lung function in 50-day-old rats. ${ }^{12}$ From limited in vitro studies, vitamin D exposure, as early as 14 weeks' gestation, seems to be an important influencing factor for the developing and growing human lung as well, but these mechanisms are far more complex and it is not known what vitamin $\mathrm{D}$ levels are related to normal lung development. ${ }^{13-15}$ It is unknown how evidence from animal studies translates to human lung development but it is possible that (abnormal) vitamin $\mathrm{D}$ status during pregnancy and in childhood affects children's lung function as well.

Studies that investigated the relation between vitamin $\mathrm{D}$ and lung function levels are scarce. The cross-sectional study of Black and Scragg ${ }^{16}$ showed that serum 25 -hydroxyvitamin $\mathrm{D}(25(\mathrm{OH}) \mathrm{D})$ was positively associated with forced expiratory volume in $1 \mathrm{~s}\left(\mathrm{FEV}_{1}\right)$ and forced vital capacity (FVC) in human adults. Another study ${ }^{17}$ reported that higher $25(\mathrm{OH}) \mathrm{D}$ levels were associated with better lung function in adults with asthma. 
No study to date has examined prospectively the $25(\mathrm{OH}) \mathrm{D}$ levels of mother and child during pregnancy and their relation to childhood lung function. Therefore the aim of this study is to investigate the association between $25(\mathrm{OH}) \mathrm{D}$ plasma levels and vitamin D supplement use, during pregnancy and in childhood, and lung function levels at school age.

\section{MATERIAL AND METHODS}

\section{Study population and data collection}

This cohort study is conducted within the prospective KOALA Birth Cohort Study in the Netherlands. The study design has previously been described in detail. ${ }^{18}$ In brief, from October 2000, healthy pregnant women with a conventional lifestyle $(\mathrm{N}=2343)$ were recruited from a prospective cohort study on pregnancy-related pelvic girdle pain $(\mathrm{N}=7020) .{ }^{19}$ In addition, pregnant women with an alternative lifestyle $(\mathrm{N}=491)$ with regard to child-rearing practices, diet (organic, vegetarian), vaccination programs and/or use of antibiotics were recruited through several 'alternative' channels like organic food shops and anthroposophic doctors' practices. All participants $(\mathrm{N}=2834)$ were enrolled between 14 and 18 weeks of gestation.

Women recruited from January 2002 onwards (conventional and alternative) were asked to consent to maternal blood sampling at $36( \pm 1)$ weeks of pregnancy $(\mathrm{N}=1365)$. Children of women from this group in whom blood collection was successful $(\mathrm{N}=1356)$ were eligible for venous blood sampling at age 2 years and lung function measurement at age 6-7 years. Information on vitamin $\mathrm{D}$ supplementation during pregnancy and in childhood was collected by questionnaires at 34 weeks of

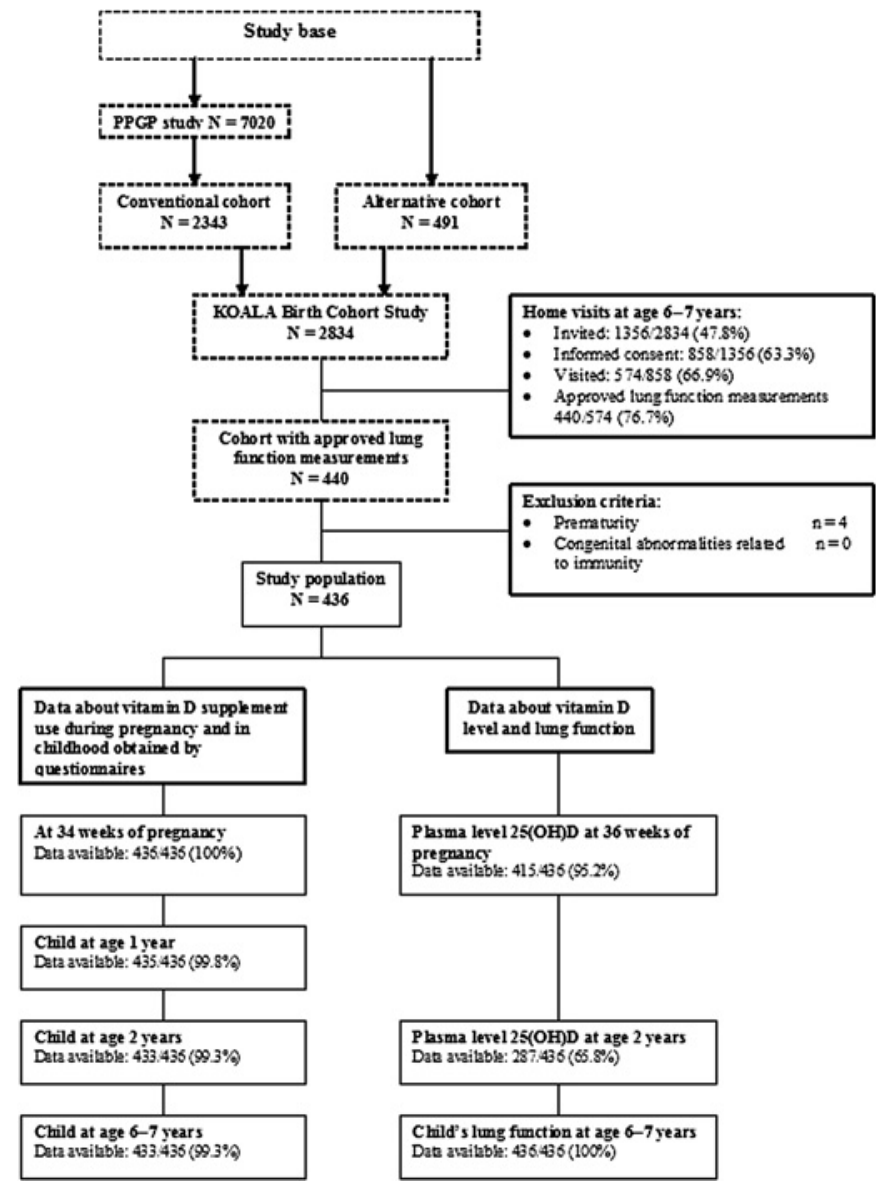

Figure 1 Flow chart. 25(OH)D, 25-hydroxyvitamin D; PPGP, Pregnancy-related Pelvic Girdle Pain Study. gestation, and when the child was aged 1, 2 and 6-7 years. Data on potential confounders were collected by questionnaires at 14 and 34 weeks of pregnancy and when the child was aged 1, 2, $4-5$, and $6-7$ years.

All parents signed informed consent forms. Ethical approval was obtained from the medical ethics committee of the Maastricht University/University Hospital Maastricht and the Netherlands Central Committee for Medical Studies on Human Subjects (CCMO).

Inclusion criteria were availability of biosamples, availability of questionnaire data at 34 weeks of pregnancy, and written informed consent. Exclusion criteria were birth at less than 37 weeks of pregnancy and congenital abnormalities related to immunity (such as Down's syndrome). Ultimately, 436 children were included in the study (figure 1).

\section{Assessment of plasma 25-hydroxyvitamin D level}

After collection by trained research assistants, the blood samples were centrifuged immediately, transported at $4^{\circ} \mathrm{C}$ and stored at $-80^{\circ} \mathrm{C}$ in a biobank until further analysis. Plasma levels of 25(OH)D were determined with an ELISA kit from Immuno Diagnostic Systems (IDS, Boldon, UK).

\section{Assessment of vitamin D supplement use}

Maternal multivitamin supplement use was assessed in the 34th week of pregnancy by questionnaire. Data on the brand and type of multivitamins, duration and trimester of use were collected and vitamin $\mathrm{D}$ dosage in the supplements was estimated using a comprehensive list of dietary supplements used at that time in the Netherlands. ${ }^{20}$ Vitamin D intake through supplements was calculated and categorised ( $0 \mu \mathrm{g} /$ day, $<10 \mu \mathrm{g} /$ day, $\geq 10 \mu \mathrm{g} /$ day). Multivitamin use was also classified into trimester(s) of use during pregnancy (no supplement use, in first trimester, in second and/or third trimester, in all trimesters) to see if this affected outcome. Also, the duration of vitamin D containing multivitamin use in pregnancy was categorised (no supplement use, during one trimester, two trimesters, or all trimesters).

Data on vitamin $\mathrm{D}$ supplement use during childhood were collected using questionnaires at ages 1,2 , and 6-7 years. At age 1 year, vitamin D supplement use was defined as use in the 11 th and/or 12th month (no, yes). Vitamin D supplementation at age 2 years was defined as use of vitamin $\mathrm{D}$ and/or $\mathrm{AD}$ supplements (no, yes) in the second year of life. During the home visits at age $6-7$ years, information on the brand and type of vitamin D supplements and the amount taken was collected. Based on these data, vitamin $\mathrm{D}$ intake through supplements was calculated and categorised $(0 \mu \mathrm{g} /$ day, $>0$ to $\leq 2.5 \mu \mathrm{g} /$ day, $>2.5 \mu \mathrm{g} /$ day). Cod liver oil supplements were not included because at age 1 and 2 years only two children (0.5\%) used these supplements and at age 6-7 years none of the children used these supplements.

\section{Assessment of lung function}

Children's lung function was assessed at age 6-7 years by trained research assistants during home visits using the handheld Medikro Spirostar USB spirometer (Medikro, Kuopio, Finland) according to the American Thoracic Society/European Respiratory Society (ATS/ERS) guidelines. ${ }^{21} 22$ Testing was performed after $10 \mathrm{~min}$ rest in an upright seated position. Each child performed forced expiratory manoeuvres that continued until three acceptable curves were achieved, with a maximum of eight attempts. Curves were acceptable if they met the reproducibility criteria defined by the ATS/ERS. ${ }^{21}{ }^{22} \mathrm{FEV}_{1}$ and FVC measures were collected and $\mathrm{z}$ scores were computed using 
Stanojevic prediction equations, ${ }^{23}$ taking into account the child's sex, age, weight and height, ambient temperature, humidity and barometric pressure measured by the assistant during the home visit.

\section{Statistical analysis}

Data analysis was performed using SPSS 15.0 for Windows. Linear regression models were used to analyse the association between $25(\mathrm{OH}) \mathrm{D}$ level, vitamin $\mathrm{D}$ supplementation and the lung function outcomes. Because women taking part in the KOALA study were recruited from two different channels (conventional and alternative), the effect of vitamin $\mathrm{D}$ exposure and recruitment group on lung function was assessed. Because the interaction terms did not reach statistical significance ( $p$ values ranged between 0.24 and 0.87 ), participants from both recruitment sources were pooled for analyses.

Quintiles of $25(\mathrm{OH}) \mathrm{D}$ were computed based on the distribution in the cohort, for the mothers and 2-year-old children separately, with the first quintile assigned as a reference group. All analyses were adjusted for recruitment group, maternal age at delivery, maternal education level, maternal smoking at 14 weeks and 34 weeks of pregnancy, alcohol consumption at 14 weeks and 34 weeks of pregnancy, maternal body mass index (BMI) before pregnancy, child's BMI at age 2 years, birth weight, exposure to environmental tobacco smoke in first 6-7 years of life, multivitamin use at age 2 years, season of blood sampling for determining $25(\mathrm{OH}) \mathrm{D}$ level, physical activity at age 4-5 years and age 6-7 years.

The results are presented as regression coefficients beta (B), unadjusted (crudeB) or adjusted (adjB) for all potential confounders, with corresponding 95\% CI. Test for trend over the quintiles of $25(\mathrm{OH}) \mathrm{D}$ and over the different groups of vitamin $\mathrm{D}$ dosage/day was calculated in the univariable and multivariable regression models. $p<0.05$ was considered statistically significant.

\section{RESULTS}

In 440 out of 2834 children included in the KOALA study, FEV 1 and FVC at age 6-7 years were measured and approved. Four children were excluded because they were born at less than 37 weeks. Of the remaining 436 children, the mother and child's $25(\mathrm{OH}) \mathrm{D}$ levels were available for 415 children $(95.2 \%)$ and 287 children (65.8\%) respectively. Information was available for all children on maternal vitamin $\mathrm{D}$ dosage/day, period and duration of vitamin $\mathrm{D}$ containing supplementation during pregnancy. Data on the child's vitamin D use at age 1, 2, and 6-7 years were available for 435 children (99.8\%), 433 children (99.3\%) and 433 children $(99.3 \%)$ respectively (figure 1$)$.

The distribution of population characteristics for the total cohort at birth, the cohort who provided biosamples, and the study population with lung function measurements at age 6-7 years is outlined in table 1 (see also appendix table A1). The recruitment period for blood sampling coincided with the period in which women were recruited from 'alternative' channels and so the subgroup that provided biosamples included proportionally more families with an alternative lifestyle than a conventional lifestyle. At age 6-7 years, mainly families with a conservative lifestyle were visited for lung function testing. The number of smokers in this group was lower compared with the total cohort.

The mean $( \pm \mathrm{SD}) 25(\mathrm{OH}) \mathrm{D}$ plasma level for mothers at 36 weeks of pregnancy was $46.0( \pm 18.2) \mathrm{nmol} /$ litre and for children at age 2 years, $73.1( \pm 22.0) \mathrm{nmol} /$ litre. The mother and child's 25(OH)D levels were not associated with lung function at age 6-7years (table 2). Analysing 25(OH)D level as a continuous variable instead of computing quintiles did not significantly change the results (results not shown).

Use of vitamin D supplementation at $<10 \mu \mathrm{g} /$ day was associated with a significantly lower $\mathrm{FEV}_{1} \mathrm{z}$ score compared with the reference group ( $0 \mu \mathrm{g} /$ day) (AdjB $-0.37 ; 95 \% \mathrm{CI}-0.69$ to -0.05 ) (table 3 ). No such association was found between vitamin $\mathrm{D}$ intake at $\geq 10 \mu \mathrm{g} /$ day and $\mathrm{FEV}_{1} \mathrm{z}$ score or FVC z score. Also, no significant trend was found towards lower lung function levels with increasing vitamin $\mathrm{D}$ dosage/day during pregnancy (adjusted $p_{\text {for trend }}=0.16$ and 0.83 , respectively).

When vitamin $\mathrm{D}$ containing multivitamins were used during the second and/or third trimesters of pregnancy the $\mathrm{FEV}_{1} \mathrm{z}$ score (AdjB -0.26; 95\% CI -0.49 to -0.03) was significantly lower compared with no use at all. Vitamin D containing multivitamins used in the first trimester or during all trimesters were not associated with lung function levels. Overall, duration of vitamin $\mathrm{D}$ containing multivitamin use in pregnancy was not associated with FVC $z$ scores or $\mathrm{FEV}_{1} \mathrm{z}$ scores. Only when mothers used these supplements during two trimesters was a significantly lower $\mathrm{FEV}_{1} \mathrm{z}$ score seen compared with the reference group ( $\mathrm{AdjB}-0.25,95 \% \mathrm{CI}-0.49$ to -0.02 ) (table 3 ).

Vitamin D use at age 1, 2, and 6-7 years was not associated with higher lung function levels in childhood (table 4). Also, when analysing vitamin D dosage/day at age 6-7 years as a continuous variable no significant associations were found (results not shown).

The results did not change significantly when only children without asthma were included in the analyses. Because of the small number of children with asthma in this study, it was not possible to analyse these children separately.

The relationship between vitamin D supplement use (yes, no) and plasma $25(\mathrm{OH}) \mathrm{D}$ level during pregnancy and at age 2 years is outlined in table 5. Vitamin D supplement use was associated with $25(\mathrm{OH}) \mathrm{D}$ level, especially when vitamin $\mathrm{D}$ production through sunlight exposure is low (low season).

A linear regression model was constructed and included factors associated with $25(\mathrm{OH}) \mathrm{D}$ level. In the season with high cutaneous vitamin $\mathrm{D}$ production, vitamin $\mathrm{D}$ containing multivitamin use, maternal obesity, and recruitment group were associated with maternal $25(\mathrm{OH}) \mathrm{D}$ level. In the low season multivitamin use increased the $25(\mathrm{OH}) \mathrm{D}$ level but maternal overweight was not statistically significantly associated with $25(\mathrm{OH}) \mathrm{D}$ level. Maternal education was not associated with maternal $25(\mathrm{OH}) \mathrm{D}$ level and was therefore not included in the final model.

For children, only vitamin D supplement use was associated with increased $25(\mathrm{OH}) \mathrm{D}$ level at age 2 years. Multivitamin use, child's overweight, maternal education, gender and recruitment group were not associated with child's $25(\mathrm{OH}) \mathrm{D}$ level and therefore were excluded from the final model.

\section{DISCUSSION}

In this birth cohort study we found no association between the mother and child's $25(\mathrm{OH}) \mathrm{D}$ level or vitamin D supplementation at age 1, 2, and 6-7 years and $\mathrm{FEV}_{1} \mathrm{z}$ scores and $\mathrm{FVC} z$ scores at age $6-7$ years. Maternal use of vitamin D at $<10 \mu \mathrm{g} /$ day, multivitamin use in the second and/or third trimester and use for two trimesters in pregnancy were associated with decreased $\mathrm{FEV}_{1} \mathrm{z}$ scores. However, there was no consistent trend towards lower lung function levels with increasing maternal vitamin $\mathrm{D}$ dosage/day or duration of multivitamin use in pregnancy. 
Table 1 Characteristics of the study population at age 6-7 years, compared with the KOALA birth cohort and the cohort that provided biosamples

\begin{tabular}{|c|c|c|c|}
\hline & $\begin{array}{l}\text { KOALA birth } \\
\text { cohort }(\mathrm{N}=2834)\end{array}$ & $\begin{array}{l}\text { Cohort with biosamples } \\
(\mathrm{N}=1356)\end{array}$ & $\begin{array}{l}\text { Study cohort at } 6-7 \\
\text { years }(N=436)\end{array}$ \\
\hline Recruitment group conventional & $2343(82.7 \%)$ & $975(71.9 \%)$ & $380(87.2 \%)$ \\
\hline Maternal age at delivery (mean $\pm S D$ ) & $32.0 \pm 3.8$ & $32.6 \pm 3.9$ & $32.4 \pm 3.6$ \\
\hline Low & $289(10.3 \%)$ & $101(7.5 \%)$ & $33(7.6 \%)$ \\
\hline Middle & $1060(37.9 \%)$ & $464(34.5 \%)$ & $169(39.1 \%)$ \\
\hline High & $1341(47.9 \%)$ & $737(54.9 \%)$ & $218(50.5 \%)$ \\
\hline Yes & $200(7.1 \%)$ & $66(4.9 \%)$ & $19(4.4 \%)$ \\
\hline \multicolumn{4}{|l|}{ Maternal smoking during late pregnancy } \\
\hline Yes & $208(7.3 \%)$ & $70(5.2 \%)$ & $22(5.0 \%)$ \\
\hline \multicolumn{4}{|l|}{ Maternal alcohol use during early pregnancy $\dagger$} \\
\hline Yes & $300(14.6 \%)$ & $163(13.8 \%)$ & $46(12.5 \%)$ \\
\hline \multicolumn{4}{|l|}{ Maternal alcohol use during late pregnancy $\ddagger$} \\
\hline \multicolumn{4}{|l|}{ Birth weight } \\
\hline$<2500 \mathrm{~g}$ & $79(2.8 \%)$ & $18(1.3 \%)$ & $3(0.7 \%)$ \\
\hline $2500-4500 \mathrm{~g}$ & $2663(94.7 \%)$ & $1288(95.6 \%)$ & $417(95.6 \%)$ \\
\hline$>4500 \mathrm{~g}$ & $70(2.5 \%)$ & $41(3.0 \%)$ & $16(3.7 \%)$ \\
\hline $\mathrm{BMI}$ of child at 2 years (mean $\pm S D$ ) & $16.4 \pm 1.4$ & $16.4 \pm 1.4$ & $16.6 \pm 1.4$ \\
\hline \multicolumn{4}{|l|}{ Use of multivitamins/minerals at age 2 years } \\
\hline Yes & $369(14.3 \%)$ & $202(16.2 \%)$ & $68(15.7 \%)$ \\
\hline \multicolumn{4}{|c|}{ Exposure to environmental tobacco smoke in first $6-7$ years of life } \\
\hline Yes & $485(24.7 \%)$ & $178(17.7 \%)$ & $71(16.3 \%)$ \\
\hline Physical activity at age $4-5$ years $($ mean $\pm S D) \S$ & $13.2 \pm 6.3$ & $13.0 \pm 6.4$ & $13.4 \pm 6.4$ \\
\hline Physical activity at age $6-7$ years (mean \pm SD) $\S$ & $15.3 \pm 6.9$ & $13.8 \pm 6.2$ & $14.6 \pm 6.3$ \\
\hline First trimester & $359(12.7 \%)$ & $200(14.8 \%)$ & $54(12.4 \%)$ \\
\hline Second and/or third trimester & $706(24.9 \%)$ & $284(21.0 \%)$ & $86(19.7 \%)$ \\
\hline All trimesters & $686(24.2 \%)$ & $337(24.9 \%)$ & $119(27.3 \%)$ \\
\hline \multicolumn{4}{|l|}{ Duration of multivitamins during pregnancy $\dagger \dagger$} \\
\hline No & $1080(38.1 \%)$ & $533(39.3 \%)$ & $177(40.6 . \%)$ \\
\hline One trimester & $388(13.7 \%)$ & $198(14.6 \%)$ & $57(13.1 \%)$ \\
\hline Two trimesters & $677(23.9 \%)$ & $286(21.2 \%)$ & $83(19.0 \%)$ \\
\hline All trimesters & $686(24.2 \%)$ & $337(24.9 \%)$ & $119(27.3 \%)$ \\
\hline \multicolumn{4}{|l|}{ Vitamin D supplement use at age 1 year } \\
\hline Yes & $1286(50.1 \%)$ & $584(45.5 \%)$ & $221(50.8 \%)$ \\
\hline \multicolumn{4}{|l|}{ Vitamin D supplement use at age 2 years } \\
\hline Yes & $1920(74.5 \%)$ & $890(71.3 \%)$ & $331(76.4 \%)$ \\
\hline \multicolumn{4}{|l|}{ Vitamin $D$ dosage/day at age $6-7$ years } \\
\hline $0 \mu \mathrm{g}$ & & & $310(71.6 \%)$ \\
\hline$>0-\leq 2.5 \mu \mathrm{g}$ & & & $82(18.9 \%)$ \\
\hline$\geq 2.5 \mu \mathrm{g}$ & & & $41(9.5 \%)$ \\
\hline
\end{tabular}

Numbers do not always add up to the total because of missing data.

*Low: primary school, preparatory vocational or lower general secondary school, middle: vocational, higher general secondary or pre-university education, high: higher vocational or academic education.

†Early pregnancy: 14th week of pregnancy.

łLate pregnancy: 34th week of pregnancy.

$\S$ In hours/week based on questionnaires.

TMeasurement during 36th week of pregnancy.

**Measurement at age 2 years.

††Vitamin D containing multivitamin supplements. 
Table 2 The mother and child's 25-hydroxyvitamin D (25(OH)D) level and lung function at age 6-7 years

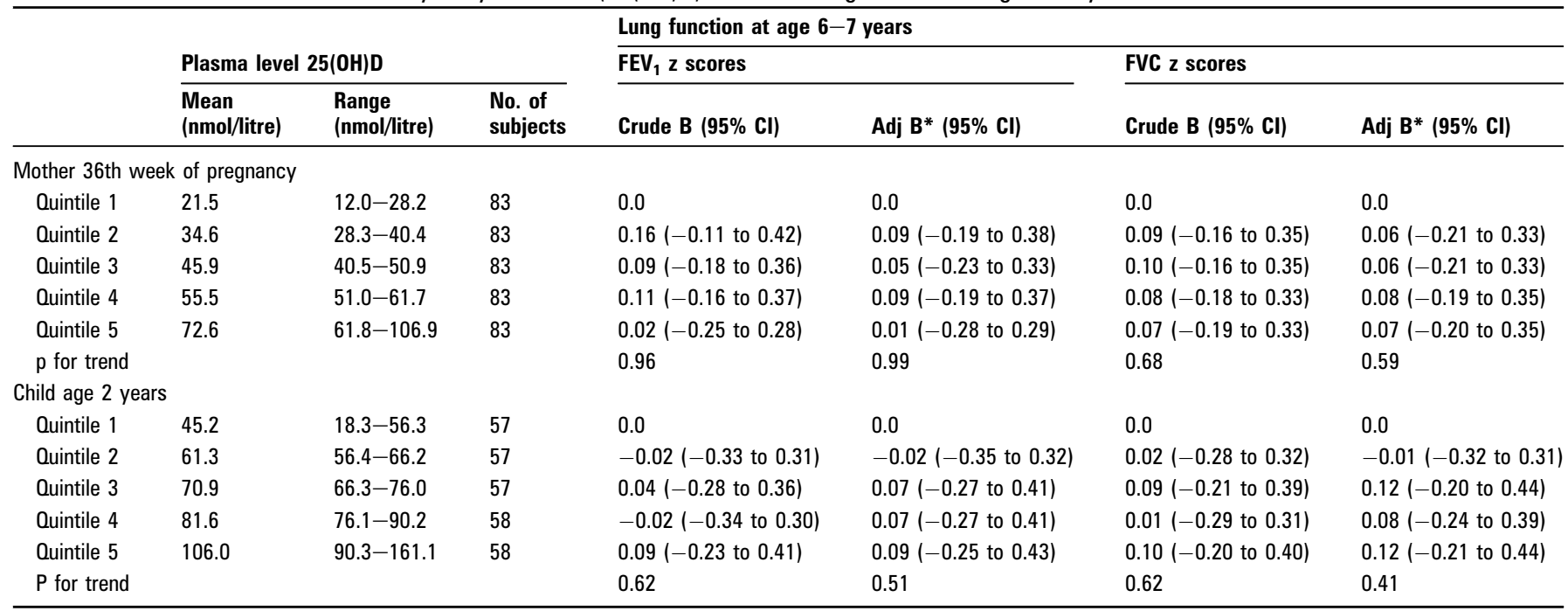

Numbers in the table do not always add up to the total because of missing data.

*Adjusted for recruitment group, maternal age at delivery, maternal education level, maternal smoking during pregnancy, maternal alcohol consumption during pregnancy, birth weight, use of multivitamins at age 2 years, environmental tobacco smoke in the first $6-7$ years of life, physical activity at age $4-5$ years and $6-7$ years, body mass index (BMI) (maternal $25(0 \mathrm{H}) \mathrm{D}$ level adjusted for maternal BMI before pregnancy, child's $25(\mathrm{OH}) \mathrm{D}$ level adjusted for child's BMI at age 2 years), season of blood sampling.

adjB, adjusted beta; $\mathrm{FEV}_{1}$, forced expiratory volume in $1 \mathrm{~s}$; FVC, forced vital capacity.

In line with our results, Devereux et $a^{24}$ reported that maternal dietary vitamin $\mathrm{D}$ intake during pregnancy and child's dietary vitamin $\mathrm{D}$ intake were not associated with better lung function levels at age 5 years old. To our knowledge, no studies to date have examined $25(\mathrm{OH}) \mathrm{D}$ levels during pregnancy and early childhood in relation to childhood lung function, although two cross-sectional studies in adults (with asthma) ${ }^{16} 17$ found, in contrast to our results, that higher $25(\mathrm{OH}) \mathrm{D}$ levels were associated with better lung function. Because the range of $25(\mathrm{OH}) \mathrm{D}$ level in our study was comparable to the other studies, $^{16}{ }^{17}$ this could not explain the different results. However, these studies measured vitamin D level and lung function cross-sectionally, making the results prone to reverse causation because healthier people with better lung function may spend more time outdoors and consequently have higher
$25(\mathrm{OH}) \mathrm{D}$ levels. Furthermore, these studies were conducted in adult populations. After early adult life, lung growth ceases and tissue damage accumulates, and vitamin $\mathrm{D}$ may influence lung function by effects on a variety of cell types important in lung tissue repair and remodelling. This study found no evidence of an effect of vitamin $\mathrm{D}$ on still developing lungs in mainly healthy school-aged children. However, this may only be apparent in healthy children if vitamin $\mathrm{D}$ status is outside the normal range or only in children with asthma or atopic predisposition. The literature reports positive effects of vitamin $\mathrm{D}$ on wheeze at age 3 years ${ }^{25}$ and 5 years, ${ }^{24}$ and on asthma. ${ }^{26}$ Xystrakis et $a l^{27}$ found that in patients with corticosteroidresistant asthma, supplementation of the active form of vitamin $\mathrm{D}_{3}$ could reverse steroid resistance through induction of interleukin -10 secreting $T$-regulatory cells, suggesting vitamin $\mathrm{D}$ is

Table 3 Maternal vitamin D dosage in multivitamins during pregnancy, period and duration of use and child's lung function at age 6-7 years

\begin{tabular}{|c|c|c|c|c|c|}
\hline & \multicolumn{5}{|c|}{ Lung function at age $6-7$ years } \\
\hline & \multirow[b]{2}{*}{ No. of women } & \multicolumn{2}{|l|}{ FEV $_{1}$ z scores } & \multicolumn{2}{|l|}{ FVC z scores } \\
\hline & & Crude B $(95 \%$ Cl) & Adj B* $(95 \% \mathrm{Cl})$ & Crude B (95\% Cl) & Adj B* $(95 \%$ Cl) \\
\hline $0 \mu \mathrm{g} /$ day (reference) & $177(40.6 \%)$ & 0.0 & 0.0 & 0.0 & 0.0 \\
\hline$<10 \mu \mathrm{g} /$ day & $38(8.7 \%)$ & $-0.37(-0.68$ to -0.07$)$ & $-0.37(-0.69$ to -0.05$)$ & $-0.15(-0.45$ to 0.15$)$ & $-0.15(-0.46$ to 0.17$)$ \\
\hline$\geq 10 \mu \mathrm{g} / \mathrm{day}$ & $221(50.7 \%)$ & $-0.13(-0.30$ to 0.04$)$ & $-0.13(-0.31$ to 0.04$)$ & $-0.02(-0.19$ to 0.15$)$ & $-0.02(-0.20$ to 0.15$)$ \\
\hline No use at all (reference) & $177(40.6 \%)$ & 0.0 & 0.0 & 0.0 & 0.0 \\
\hline First trimester & $54(12.4 \%)$ & $-0.19(-0.45$ to 0.08$)$ & $-0.17(-0.44$ to 0.10$)$ & $-0.12(-0.38$ to 0.14$)$ & $-0.11(-0.38$ to 0.16$)$ \\
\hline Second and/or third trimester & $86(19.7 \%)$ & $-0.25(-0.48$ to -0.03$)$ & $-0.26(-0.49$ to -0.03$)$ & $-0.11(-0.33$ to 0.11$)$ & $-0.12(-0.34$ to 0.11$)$ \\
\hline All trimesters & $119(27.3 \%)$ & $-0.09(-0.30$ to 0.11$)$ & $-0.10(-0.31$ to 0.11$)$ & $0.05(-0.15$ to 0.25$)$ & $0.05(-0.16$ to 0.25$)$ \\
\hline \multicolumn{6}{|c|}{ Duration of vitamin $D$ containing multivitamin use during pregnancy } \\
\hline No use at all (reference) & $177(40.6 . \%)$ & 0.0 & 0.0 & 0.0 & 0.0 \\
\hline
\end{tabular}

Numbers in the table do not always add up to the total because of missing data.

*Adjusted for recruitment group, maternal age at delivery, maternal education level, maternal smoking during pregnancy, maternal alcohol consumption during pregnancy, birth weight, use of multivitamins at age 2 years, environmental tobacco smoke, physical activity at age $4-5$ years and $6-7$ years.

adjB, adjusted beta; FEV $_{1}$, forced expiratory volume in $1 \mathrm{~s}$; FVC, forced vital capacity. 
Table 4 Child's vitamin D supplement use at age 1 and 2 years, vitamin D dosage at age $6-7$ years and lung function at age $6-7$ years

\begin{tabular}{|c|c|c|c|c|c|}
\hline & \multicolumn{5}{|c|}{ Lung function at age $6-7$ years } \\
\hline & \multirow[b]{2}{*}{ No. of children } & \multicolumn{2}{|l|}{$\mathrm{FEV}_{1}$ z scores } & \multicolumn{2}{|l|}{ FVC z scores } \\
\hline & & Crude B (95\% CI) & Adj B* $(95 \%$ Cl) & Crude B (95\% Cl) & Adj B* $(95 \% \mathrm{Cl})$ \\
\hline \multicolumn{6}{|c|}{ Vitamin D supplement use at age 1 year } \\
\hline No (reference) & $214(49.2 \%)$ & 0.0 & 0.0 & 0.0 & 0.0 \\
\hline Yes & $221(50.8 \%)$ & $0.17(-0.03$ to 0.37$)$ & $0.17(-0.03$ to 0.37$)$ & $0.07(-0.09$ to 0.24$)$ & $0.07(-0.10$ to 0.23$)$ \\
\hline \multicolumn{6}{|c|}{ Vitamin D supplement use at age 2 years } \\
\hline No (reference) & $102(23.6 \%)$ & 0.0 & 0.0 & 0.0 & 0.0 \\
\hline \multicolumn{6}{|c|}{ Vitamin $D$ dosage/day at age $6-7$ years } \\
\hline $0 \mu \mathrm{g}$ (reference) & $310(71.6 \%)$ & 0.0 & 0.0 & 0.0 & 0.0 \\
\hline$>0 \mu \mathrm{g}$ to $\leq 2.5 \mu \mathrm{g}$ & $82(18.9 \%)$ & $-0.11(-0.33$ to 0.11$)$ & $-0.13(-0.35$ to 0.09$)$ & $-0.01(-0.21$ to 0.20$)$ & $-0.02(-0.24$ to 0.20$)$ \\
\hline$>2.5 \mu \mathrm{g}$ & $41(9.5 \%)$ & $-0.19(-0.48$ to 0.09$)$ & $-0.22(-0.51$ to 0.08$)$ & $-0.08(-0.36$ to 0.20$)$ & $-0.11(-0.40$ to 0.18$)$ \\
\hline$p$ for trend & & 0.12 & 0.09 & 0.64 & 0.50 \\
\hline
\end{tabular}

Numbers in the table do not always add up to the total because of missing data.

*Adjusted for recruitment group, maternal age at delivery, maternal education level, maternal smoking during pregnancy, maternal alcohol consumption during pregnancy, birth weight, use of multivitamins at age 2 years, environmental tobacco smoke, physical activity at age $4-5$ years and $6-7$ years.

adjB, adjusted beta; $\mathrm{FEV}_{1}$, forced expiratory volume in $1 \mathrm{~s}$; FVC, forced vital capacity.

clinically relevant for asthma. However, others reported that vitamin $\mathrm{D}$ supplementation in infancy may increase the risk of asthma and allergies. ${ }^{28} 29$ Gale et al reported that a high maternal $25(\mathrm{OH}) \mathrm{D}$ level during pregnancy was associated with an increased risk of asthma at age 9 years. ${ }^{30}$ Ginde et al ${ }^{31}$ found that vitamin $\mathrm{D}$ decreases risk of respiratory infections (and wheeze). This can lead to less cumulate airway damage in predisposed children and may prevent clinical asthma in some cases.

This study did not consider dietary vitamin $\mathrm{D}$ intake because it is naturally present in very few foods we eat, for example oily fish, fish liver oil, egg yolk and offal. ${ }^{32}$ Also, vitamin D supplements contain significantly more vitamin D than vitamin Dcontaining foods ${ }^{33}$ and the bioavailability of vitamin $\mathrm{D}$ from food is less than from supplements (50\% vs $55-99 \%) .{ }^{34}$

This study was not able to investigate vitamin $\mathrm{D}$ supplementation in pregnancy as a standalone supplement. Therefore

Table 5 Determinants of the mother and child's 25-hydroxyvitamin D $(25(\mathrm{OH}) \mathrm{D}))$ level

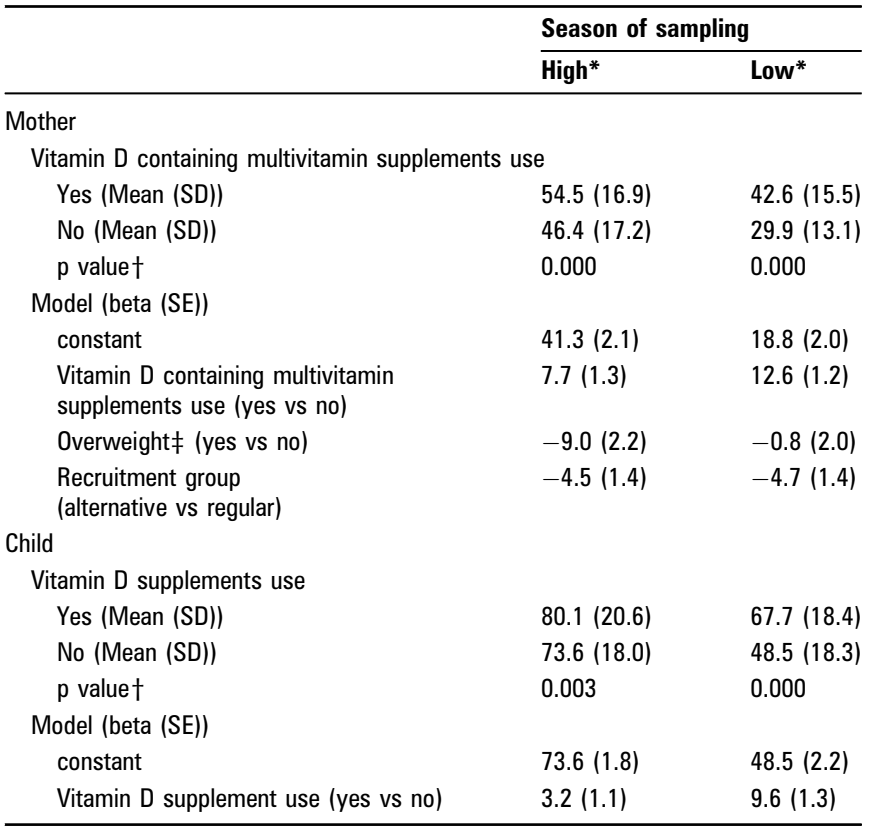

*High, season with high cutaneous vitamin D production (April-October); low, season with low cutaneous vitamin $D$ production (November-March).

†Analysis of variance (ANOVA).

$\ddagger$ verweight is defined as body mass index $>90$ th percentile. the possibility that the findings were confounded by other vitamins used cannot be completely excluded. For example, vitamin $\mathrm{A}$ and $\mathrm{D}$ both bind to the retinoid $\mathrm{X}$ receptor and therefore may antagonise each other's action. It has also been suggested that vitamin $\mathrm{A}$ and $\mathrm{E}$ in pregnancy may improve childhood lung function. ${ }^{4}$ However, in the Netherlands, the regular multivitamin supplements contain only a limited amount of vitamin A (and the pregnancy supplements contain none because of teratogenicity). Also, the vitamin $\mathrm{E}$ amount in the multivitamin supplements in the Netherlands is about $30-50 \%$ less compared with the study described above, ${ }^{4}$ making a possible influence on our findings small.

$25(\mathrm{OH}) \mathrm{D}$ level is considered the most accurate measurement of short-term vitamin $\mathrm{D}$ status because it takes diet, supplements and sunlight exposure into account. However, this onetime measurement might not reflect a person's vitamin D status over the course of a year. ${ }^{33}$ Because blood samples were taken at 36 weeks of pregnancy in this study, the relationship between $25(\mathrm{OH}) \mathrm{D}$ levels in early pregnancy and childhood lung function could not be assessed. Measuring vitamin D intake through supplements is considered a more accurate assessment of longterm vitamin $\mathrm{D}$ status. ${ }^{33}$ Because information was collected on dosage and duration of supplement use for mothers in pregnancy and children aged 6-7 years, the intake of vitamin D from supplements could be accurately determined. In addition, $25(\mathrm{OH}) \mathrm{D}$ levels and questions about supplemental intake complement each other, and so a combination of these exposition factors was used to achieve vitamin $\mathrm{D}$ status throughout a person's lifetime.

This study had the advantage of a prospective follow-up with relatively short intervals between questionnaires, decreasing recall bias. Self-reporting questionnaires are a valid method for assessing supplement use. ${ }^{35}$ The study populations' characteristics after 6-7 years of follow-up were comparable to those at birth, making bias as a result of differential loss to follow-up unlikely. Missing data due to non-response could have influenced the results, but this is expected to be non-differential.

Measurement and assessment of lung function were performed in line with the ATS/ERS guidelines. ${ }^{21} 22$ According to Miller et $a^{22}$ acceptable spirometry curves can be obtained in children as young as 5 years if these guidelines are followed.

In conclusion, the study found that, in contrast to previous studies in adults and adolescents, there was no association between 25(OH)D level, vitamin D supplement use in childhood 
or recommended vitamin $\mathrm{D}$ dosage of $\geq 10 \mu \mathrm{g}$ /day during pregnancy and lung function levels at age $6-7$ years.

Acknowledgements We thank the children and their parents who participated in the KOALA Birth Cohort Study. In addition, we thank H. Cremers and P. Beekhof for their excellent assistance in the analysis of 25(OH)D level.

Funding This study was financially supported by grants from the Netherlands Asthma Foundation (grant numbers 3.2.07.022 and 3.2.03.48), the Netherlands Organization for Health Research and Development (ZonMw Prevention Program number 1.210-00-090), Royal Friesland Foods, Triodos Foundation, Phoenix Foundation, Raphaël Foundation, Iona Foundation, Foundation for the Advancement of Heilpedagogie, The Netherlands Brain Foundation, and the Netherlands Ministry of Public Health, Welfare and Sport.

Competing interests None

Ethics approval Ethical approval was obtained from the medical ethics committee of the Maastricht University/University Hospital Maastricht and the Netherlands Central Committee for Medical Studies on Human Subjects (CCMO).

Provenance and peer review Not commissioned; externally peer reviewed.

\section{REFERENCES}

1. Carlsen KH, Carlsen KC. Respiratory effects of tobacco smoking on infants and young children. Paediatr Respir Rev 2008; 9:11-19.

2. Hanrahan JP, Tager IB, Segal MR, et al. The effect of maternal smoking during pregnancy on early infant lung function. Am Rev Respir Dis 1992;145:1129-35

3. Berntsen S, Wisloff T, Nafstad P, et al. Lung function increases with increasing level of physical activity in school children. Pediatr Exerc Sci 2008;20:402-10.

4. Devereux G, Turner SW, Craig LC, et al. Low maternal vitamin E intake during pregnancy is associated with asthma in 5-year-old children. Am J Respir Crit Care Med 2006:174:499-507.

5. Shaheen SO, Northstone K, Newson RB, et al. Dietary patterns in pregnancy and respiratory and atopic outcomes in childhood. Thorax 2009;64:411-17.

6. Gilliland FD, Berhane KT, Li YF, et al. Children's lung function and antioxidant vitamin, fruit, juice, and vegetable intake. Am J Epidemiol 2003;158:576-84.

7. Litonjua AA. Childhood asthma may be a consequence of vitamin D deficiency. Curr Opin Allergy Clin Immunol 2009;9:202-7.

8. Burri PH. Fetal and postnatal development of the lung. Annu Rev Physiol 1984:46:617-28.

9. Nguyen M, Guillozo H, Garabedian M, et al. Lung as a possible additional target organ for vitamin D during fetal life in the rat. Biol Neonate 1987;52(4):232-40.

10. Marin L, Dufour ME, Tordet C, et al. 1,25(OH)2D3 stimulates phospholipid biosynthesis and surfactant release in fetal rat lung explants. Biol Neonate 1990;57:257-60.

11. Marin L, Dufour ME, Nguyen TM, et al. Maturational changes induced by 1alpha,25-dihydroxyvitamin D3 in type II cells from fetal rat lung explants. Am $J$ Physiol 1993;265:L45-52

12. Gaultier C, Harf A, Balmain N, et al. Lung mechanics in rachitic rats. Am Rev Respir Dis 1984:130:1108-10.

13. Rehan VK, Torday JS, Peleg S, et al. 1Alpha,25-dihydroxy-3-epi-vitamin D3, a natural metabolite of 1alpha,25-dihydroxy vitamin D3: production and biological activity studies in pulmonary alveolar type II cells. Mol Genet Metab 2002;76:46-56

14. Lunghi B, Meacci E, Stio M, et al. 1,25-Dihydroxyvitamin D3 inhibits proliferation of IMR-90 human fibroblasts and stimulates pyruvate kinase activity in confluent-phase cells. Mol Cell Endocrinol 1995;115:141-8.

15. Stio M, Celli A, Lunghi B, et al. Vitamin D receptor in IMR-90 human fibroblasts and antiproliferative effect of 1,25-dihydroxyvitamin D3. Biochem Mol Biol Int 1997:43:1173-81

16. Black PN, Scragg R. Relationship between serum 25-hydroxyvitamin d and pulmonary function in the third national health and nutrition examination survey Chest 2005; 128:3792-8.

17. Sutherland ER, Goleva E, Jackson LP, et al. Vitamin D levels, lung function and steroid response in adult asthma. Am J Respir Crit Care Med 2010;187:699-704.

18. Kummeling I, Thijs C, Penders J, et al. Etiology of atopy in infancy: the KOALA Birth Cohort Study. Pediatr Allergy Immunol 2005;16:679-84.

19. Bastiaanssen JM, de Bie RA, Bastiaenen $\mathrm{CH}$, et al. Etiology and prognosis of pregnancy-related pelvic girdle pain: design of a longitudinal study. BMC Public Health 2005:5:1.

20. Anon. Overzicht van vitaminepreparaten (overview of vitamins, minerals and food supplements). Gezond (Health Guide of the Dutch Consumers Federation) 2002;32 (Suppl 1):34-49.

21. Miller MR, Crapo R, Hankinson J, et al. General considerations for lung function testing. Eur Respir J 2005:26:153-61.

22. Miller MR, Hankinson J, Brusasco V, et al. Standardisation of spirometry. Eur Respir $J$ 2005;26:319-38

23. Stanojevic S, Wade A, Stocks J, et al. Reference ranges for spirometry across all ages: a new approach. Am J Respir Crit Care Med 2008;177:253-60.

24. Devereux G, Litonjua AA, Turner SW, et al. Maternal vitamin D intake during pregnancy and early childhood wheezing. Am J Clin Nutr 2007:85:853-9.
25. Camargo CA Jr, Rifas-Shiman SL, Litonjua AA, et al. Maternal intake of vitamin D during pregnancy and risk of recurrent wheeze in children at 3 y of age. Am J Clin Nutr 2007:85:788-95.

26. Erkkola M, Kaila $\mathrm{M}, \mathrm{Nwaru} \mathrm{Bl}$, et al. Maternal vitamin $\mathrm{D}$ intake during pregnancy is inversely associated with asthma and allergic rhinitis in 5-year-old children. Clin Exp Allergy 2009;39:875-82.

27. Xystrakis $\mathbf{E}$, Kusumakar $\mathrm{S}$, Boswell $\mathrm{S}$, et al. Reversing the defective induction of IL-10-secreting regulatory T cells in glucocorticoid-resistant asthma patients. J Clin Invest 2006:116:146-55.

28. Hyppönen $\mathbf{E}$, Sovio U, Wjst M, et al. Infant vitamin D supplementation and allergic conditions in adulthood: northern Finland birth cohort 1966. Ann N Y Acad Sci 2004:1037:84-95.

29. Wjst M. The vitamin D slant on allergy. Pediatr Allergy Immunol 2006;17:477-83.

30. Gale CR, Robinson SM, Harvey NC, et al. Maternal vitamin D status during pregnancy and child outcomes. Eur J Clin Nutr 2008:62:68-77.

31. Ginde AA, Mansbach JM, Camargo CA Jr. Vitamin D, respiratory infections, and asthma. Curr Allergy Asthma Rep 2009;9:81-7.

32. Lamberg-Allardt C. Vitamin D in foods and as supplements. Prog Biophys Mol Biol 2006:92:33-8

33. Millen AE, Bodnar LM. Vitamin D assessment in population-based studies: a review of the issues. Am J Clin Nutr 2008;87:1102S-5S.

34. Netherlands HCOT. Dietary reference intakes: calcium, vitamin D, thiamin, riboflavin, niacin, pantothenic acid, and biotin. The Hague: Health Council of the Netherlands, 2000; publication no. 2000/122.

35. Satia-Abouta J, Patterson RE, King IB, et al. Reliability and validity of self-report of vitamin and mineral supplement use in the vitamins and lifestyle study. $A m \mathrm{~J}$ Epidemiol 2003;157:944-54

\section{APPENDIX}

Table A1 Characteristics of children for whom vitamin D status was available versus unavailable

\begin{tabular}{|c|c|c|}
\hline & \multicolumn{2}{|c|}{ Child's vitamin D status } \\
\hline & $\begin{array}{l}\text { Available } \\
\text { (N=287) }\end{array}$ & $\begin{array}{l}\text { Unavailable } \\
\text { ( } N=149)\end{array}$ \\
\hline Recruitment group conventional & $246(85.7 \%)$ & $134(89.9 \%)$ \\
\hline Maternal age at delivery (mean \pm SD) & $32.5 \pm 3.6$ & $32.2 \pm 3.6$ \\
\hline \multicolumn{3}{|l|}{ Maternal education* } \\
\hline Low & $21(7.3 \%)$ & $12(8.2 \%)$ \\
\hline Middle & $113(39.5 \%)$ & $56(38.4 \%)$ \\
\hline High & $142(49.7 \%)$ & $76(52.0 \%)$ \\
\hline Other & $10(3.5 \%)$ & $2(1.4 \%)$ \\
\hline \multicolumn{3}{|l|}{ Maternal smoking during early pregnancy $\dagger$} \\
\hline Yes & $13(4.6 \%)$ & $6(4.0 \%)$ \\
\hline \multicolumn{3}{|l|}{ Maternal smoking during late pregnancy‡ } \\
\hline Yes & $15(5.2 \%)$ & $7(4.7 \%)$ \\
\hline \multicolumn{3}{|l|}{ Maternal alcohol use during early pregnancy $\dagger$} \\
\hline Yes & $27(11.4 \%)$ & $19(14.6 \%)$ \\
\hline \multicolumn{3}{|l|}{ Maternal alcohol use during late pregnancy } \\
\hline Yes & $45(15.7 \%)$ & $25(16.8 \%)$ \\
\hline Maternal BMI before pregnancy (mean \pm SD) & $24.0 \pm 3.9$ & $23.3 \pm 3.4$ \\
\hline \multicolumn{3}{|l|}{ Gender } \\
\hline Boy & $127(44.3 \%)$ & $71(47.7 \%)$ \\
\hline \multicolumn{3}{|l|}{ Birth weight } \\
\hline$<2500 \mathrm{~g}$ & $1(0.3 \%)$ & $2(1.4 \%)$ \\
\hline $2500-4500 \mathrm{~g}$ & $276(96.2 \%)$ & $141(94.6 \%)$ \\
\hline$>4500 \mathrm{~g}$ & $10(3.5 \%)$ & $6(4.0 \%)$ \\
\hline Child's BMl at 2 years (mean $\pm S D$ ) & $16.4 \pm 1.3$ & $16.8 \pm 1.6$ \\
\hline \multicolumn{3}{|l|}{ Use of multivitamins/minerals at age 2 years } \\
\hline Yes & $46(16.1 \%)$ & $22(15.0 \%)$ \\
\hline \multicolumn{3}{|l|}{$\begin{array}{l}\text { Exposure to environmental tobacco smoke in } \\
\text { first } 6-7 \text { years of life }\end{array}$} \\
\hline Yes & $47(16.4 \%)$ & $24(16.1 \%)$ \\
\hline Physical activity at age $4-5$ years (mean $\pm S D$ ) & $13.5 \pm 6.6$ & $13.2 \pm 6.0$ \\
\hline Physical activity at age $6-7$ years (mean $\pm S D$ ) & $14.9 \pm 6.4$ & $14.2 \pm 6.2$ \\
\hline
\end{tabular}

BMI, body mass index.

* Low: primary school, preparatory vocational or lower general secondary school, middle: vocational, higher general secondary or pre-university education, high: higher vocational or academic education.

†Early pregnancy: 14th week of pregnancy.

łLate pregnancy: 34 th week of pregnancy. 